\title{
Neuromodulation of Spike-Timing Precision in Sensory Neurons
}

\author{
Cyrus P. Billimoria, ${ }^{1}$ Ralph A. DiCaprio, ${ }^{2}$ John T. Birmingham, ${ }^{3}$ L. F. Abbott, ${ }^{1}$ and Eve Marder ${ }^{1}$ \\ ${ }^{1}$ Volen Center and Biology Department, Brandeis University, Waltham, Massachusetts 02454, ${ }^{2}$ Department of Biological Sciences, Ohio University, Athens, \\ Ohio 45701, and ${ }^{3}$ Department of Physics, Santa Clara University, Santa Clara, California 95053
}

The neuropeptide allatostatin decreases the spike rate in response to time-varying stretches of two different crustacean mechanoreceptors, the gastropyloric receptor 2 in the crab Cancer borealis and the coxobasal chordotonal organ (СВCT0) in the crab Carcinus maenas. In each system, the decrease in firing rate is accompanied by an increase in the timing precision of spikes triggered by discrete temporal features in the stimulus. This was quantified by calculating the standard deviation or "jitter" in the times of individual identified spikes elicited in response to repeated presentations of the stimulus. Conversely, serotonin increases the firing rate but decreases the timing precision of the CBCTO response. Intracellular recordings from the afferents of this receptor demonstrate that allatostatin increases the conductance of the neurons, consistent with its inhibitory action on spike rate, whereas serotonin decreases the overall membrane conductance. We conclude that spike-timing precision of mechanoreceptor afferents in response to dynamic stimulation can be altered by neuromodulators acting directly on the afferent neurons.

Key words: stretch receptor; reliability; coding; neuropeptide; crustacea; STG

\section{Introduction}

Numerous studies have demonstrated that, in response to repeated presentations of an identical time-varying stimulus, neurons can generate very reproducible firing patterns in which individual identifiable spikes in the train are precisely replicated trial-to-trial (Barlow, 1963; Bryant and Segundo, 1976; de Ruyter van Steveninck et al., 1997). The precision of the neural response can be quantified by calculating the standard deviation or "jitter" in the timing of these individual spikes averaged over all spikes and trains. Very small jitter appears to be a feature common to a wide variety of neurons: jitter of $\sim 1 \mathrm{~ms}$ or smaller in response to current injection stimuli have been reported both for neurons in the vertebrate CNS (Mainen and Sejnowski, 1995; Beierholm et al., 2001) and for Aplysia motor neurons (Hunter et al., 1998; Szücs et al., 2004). Comparably small jitters have been measured in neurons in the vertebrate retina (Berry et al., 1997; Berry and Meister, 1998; Uzzell and Chichilnisky, 2004) and lateral geniculate nucleus (Reinagel and Reid, 2000; Liu et al., 2001; Reinagel and Reid, 2002) in response to time-varying visual stimuli. In response to the onset of a stimulus, the timing of the first spikes produced by neurons in the auditory cortex also can be quite precise (Heil, 1997; Phillips et al., 2002; Elhilali et al., 2004; Hurley and Pollak, 2005).

Received 0ct. 31, 2005; revised April 18, 2006; accepted April 18, 2006.

This work was supported by National Institutes of Health Grant 17813 (E.M.), National Science Foundation Grant IBN9904633 (R.A.D.), and by an award from Research Corporation (J.T.B.).

Correspondence should be addressed to Ralph A. DiCaprio, Department of Biological Sciences, Ohio University, Athens, 0H 45701. E-mail: rdicaprio1@ohiou.edu.

C. P. Billimoria's present address: Hearing Research Center, Department of Biomedical Engineering, Boston University, Boston, MA 02215.

DOI:10.1523/JNEUROSCI.4659-05.2006

Copyright $\odot 2006$ Society for Neuroscience $\quad$ 0270-6474/06/265910-10\$15.00/0
Common sense dictates that, everything else being equal, decreased jitter should improve the description of the stimulus carried by a sensory spike train. Mathematical analysis confirms that increased spike-timing precision enhances information transmission by neurons. For example, estimates of stimulus features (Bialek et al., 1991; Rieke et al., 1997) for sensory interneurons in the cricket cercal system improved when the spike trains were "dejittered" (Aldworth et al., 2005). Moreover, Rokem et al. (2006) recently showed that information transfer (Strong et al., 1998) by grasshopper auditory receptors increased when spike time jitter was lowered by changing stimulus statistics, primarily because of a decrease in spike train noise entropy. They also suggested that very precisely timed spikes, having jitter as low as 0.15 ms, may encode important features of natural stimuli.

One would expect, however, that jitter should be much less crucial when the stimulus is encoded in the mean firing rate (Adrian and Zotterman, 1926; Redman et al., 1968) rather than in the timing or patterns of the individual spikes (MacKay and McCulloch, 1952; Barlow, 1963; Werner and Mountcastle, 1965; Segundo et al., 1966; Sanderson et al., 1973; Bialek and Rieke, 1992; Theunissen and Miller, 1995; deCharms and Zador, 2000). The relative importance of jitter might vary even for a given neuron, if it encodes a stimulus that fluctuates on a number of time scales. In particular, to describe optimally a static or slowly varying stimulus, it might be advantageous to allow jitter to increase, if this could be accompanied by an increase in firing rate or dynamic range, and if the jitter were small compared with the time scale over which the mean firing rate changes.

In this paper, we describe how two neuromodulatory substances affect the precision of responses of mechanosensory neurons to dynamic stimuli in two different crustacean sensorimotor systems, the gastropyloric receptor 2 (GPR2) in Cancer borealis 
and the coxobasal chordotonal organ (CBCTO) in Carcinus maenas. In both systems, we observed that application of the neuropeptide allatostatin (AST) decreased both the spike rate and jitter and that, in the CBCTO, these results were accompanied by a decrease in membrane resistance. Exposure to serotonin had the opposite effect in CBCTO, increasing membrane resistance, spike rate, and jitter. These findings suggest that changes in jitter and firing rate may be correlated and that neuromodulation provides a mechanism by which the balance between temporal precision and robust firing may be shifted.

\section{Materials and Methods}

Animals and solutions. Studies of GPR2 were made using adult male crabs (C. borealis), which were obtained from local seafood suppliers in Boston, MA, and kept in aerated aquaria at $12-15^{\circ} \mathrm{C}$ until used. In GPR2 experiments, physiological saline with the following composition (in $\mathrm{mm}$ ) was used: $440 \mathrm{NaCl}, 11 \mathrm{KCl}, 13 \mathrm{CaCl}_{2}, 26 \mathrm{MgCl}_{2}, 5$ maleic acid, and 11 Trizma base, $\mathrm{pH}$ 7.4-7.5. Studies of the CBCTO were made using adult male and female crabs (C. maenas) obtained from Ocean Resource (Sedgewick, ME). The saline for CBCTO experiments had the following composition (in mM): $500 \mathrm{NaCl}, 12 \mathrm{KCl}, 12 \mathrm{CaCl}_{2}, 20 \mathrm{MgCl}_{2}, 5$ maleic acid, and 12 Trizma base, $\mathrm{pH}$ 7.4. In all experiments the peptide allatostatin III type A (Bachem, Torrance, CA) was dissolved in distilled water at $10^{-3} \mathrm{M}$, stored at $-20^{\circ} \mathrm{C}$, and diluted into saline immediately before use. Serotonin (5-HT; Sigma, St. Louis, MO) stock solutions were made immediately before use in each experiment. Saline containing $2 \times 10^{-7} \mathrm{M}$ tetrodotoxin (TTX; Sigma) was used to block action potential production in the experiments in which the CBCTO current-voltage $(I-V)$ relationships were determined.

GPR2 electrophysiology. The GPR2 neuron is a muscle stretch receptor (Katz et al., 1989) with a response to slowly varying (low-pass filtered with cutoff $<1 \mathrm{~Hz}$ ) muscle movements that can be described accurately in terms of the average spike rate (Birmingham et al., 1999). It innervates the gm9 and cpv3a muscles [nomenclature from Maynard and Dando (1974)] in the crab's foregut. Preparations consisting of gm9, cpv3a, the lateral ventricular nerve $(l v n)$, and the gastropyloric nerve $(g p n)$ were dissected as described previously (Birmingham et al., 1999) and placed flat in $5 \mathrm{ml}$ Sylgard-lined (Dow Corning, Midland, MI) dishes. During experiments, the bath volume was $\sim 3 \mathrm{ml}$, and the preparation was continuously superfused ( $4-5 \mathrm{ml} / \mathrm{min}$ ) with saline cooled to a regulated temperature between 9 and $11^{\circ} \mathrm{C}$. Extracellular recordings of GPR2 spikes were made from the gpn using glass suction electrodes, amplified by an A-M Systems (Carlsborg, WA) 1700 differential amplifier and recorded using an Axon Instruments (Union City, CA) Digidata interface board. Analysis of GPR2 activity was done using Matlab (The MathWorks, Natick, MA) and Spike2 [Cambridge Electronic Design (CED), Cambridge, UK] scripts. GPR2 spikes are the largest sensory units on the $g p n$ (Katz et al., 1989) and were identified in extracellular recordings using a window discriminator on the peak spike amplitudes. Extracellular recordings were made using a sample rate of $10 \mathrm{kHz}$, providing a temporal resolution of $100 \mu \mathrm{s}$.

GPR2 stimulation. In all experiments, the cpv3a muscle was stretched to elicit GPR2 spikes, and preparations were pinned to minimize the movement of gm9. One insertion of cpv3a was pinned down to the dish (Fig. 1A) and the other was attached to a Grass (Quincy, MA) forcedisplacement transducer (Model FT03) using No. 6 silk suture thread (FST, Foster City, CA). The movement arm of the transducer was in turn connected to an audio speaker. Analog waveforms from the Digidata board were used to drive the audio speaker electrically and hence stretch cpv3a. The waveforms used in GPR2 experiments were low-pass-filtered $(20 \mathrm{~Hz})$ Gaussian white noise.

CBCTO dissection. The CBCTO is a proprioceptor that monitors position, velocity, and acceleration of a joint in the crab's leg (Bush, 1965; Gamble and DiCaprio, 2003). In contrast to GPR2, the CBCTO is a relatively broad band receptor which can respond to movements at frequencies up to $200 \mathrm{~Hz}$ with the peak gain occurring at $90-110 \mathrm{~Hz}$ (Gamble and DiCaprio, 2003). The CBCTO spans the coxobasal (CB) joint in the crab leg and consists of an elastic strand innervated by $\sim 80$ afferent neurons. Isolated CBCTO-thoracic ganglion preparations were dissected
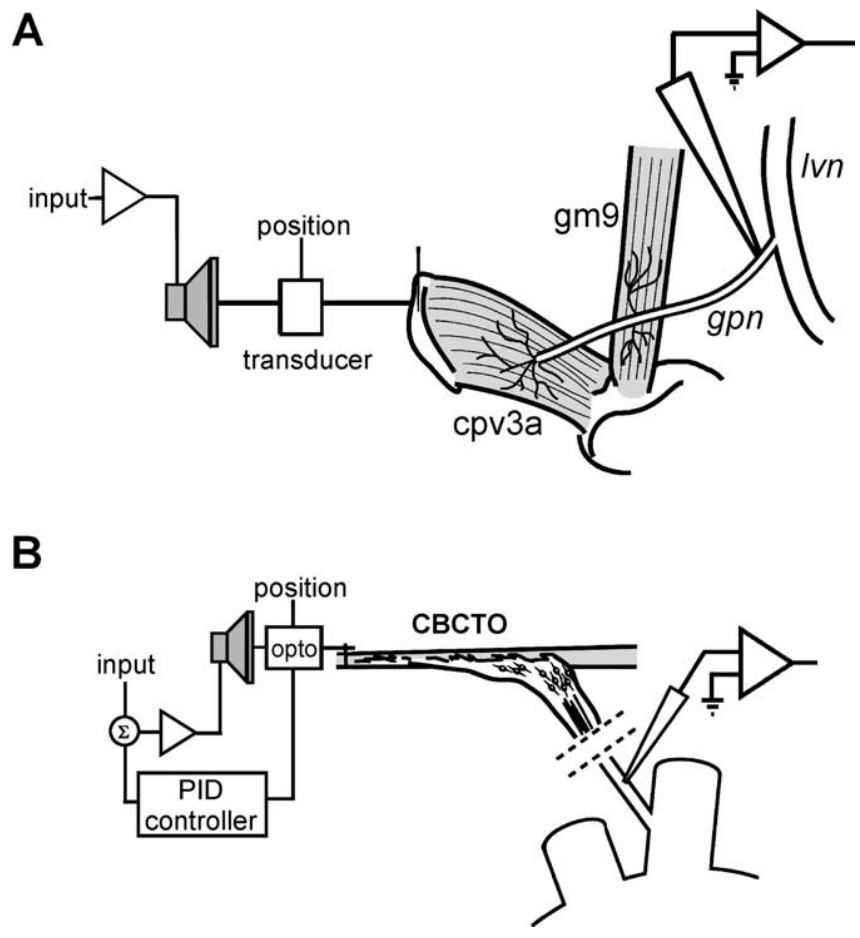

Figure 1. Schematic diagram of the two experimental preparations. A, GPR2 preparation from the crab C. borealis. The cpv3a muscle is attached to and stretched by the movement of a loudspeaker while spikes from the GPR2 axon are recorded by a suction electrode on the gastropyloric nerve ( $g p n)$. $B$, Isolated preparation of the CBCTO from the fifth leg of the common green shore crab C. maenas. The elastic strand of the CBCT0 is connected to an electromechanical puller monitored by an optical position sensor (opto) and controlled by a PID controller operating in an active length feedback mode. Intracellular recordings are made from a single chordotonal afferent axon in the chordotonal nerve distal to the thoracic ganglion, which is partially outlined at the bottom right of the figure.

as described previously (Gamble and DiCaprio, 2003). The ganglion was pinned to a Sylgard substrate and continuously superfused with chilled oxygenated saline at a rate of $4-6 \mathrm{ml} / \mathrm{min}$. The connective tissue surrounding the origin of the CBCTO was securely pinned to the substrate, and the $\mathrm{CB}$ nerve was desheathed for most of its length with fine forceps. The nerve was placed on a small Sylgard block and pinned by the remaining connective tissue to stabilize it for intracellular recording (Fig. $1 B$ ).

CBCTO electrophysiology. Two types of intracellular recordings from individual CBCTO afferents were made. In most experiments, simultaneous intracellular recordings from two CBCTO afferents were made from the $\mathrm{CB}$ nerve with glass microelectrodes filled with $2 \mathrm{~m} \mathrm{KAc}$ and amplified by an NPI (Tamm, Germany) model 5L electrometer and a WPI (Sarasota, FL) model 767 electrometer. Approximately 10-12 of the CBCTO afferent somata are located adjacent to the $\mathrm{CB}$ connective tissue strand and were accessible for intracellular recording and current injection. In 10 experiments, somatic recordings were made from a preparation in which the chordotonal organ was dissected from the surrounding connective tissue and pinned to a Sylgard block. In four of these 10 experiments, simultaneous recordings were also made from the axon of the cell in the CB nerve. All signals were sampled on-line by a CED Power-1401 interface controlled by CED Spike2 software. The sample rate for the receptor position was $2.5 \mathrm{kHz}$, whereas the intracellular recordings were sampled at $12.5 \mathrm{kHz}$ with an underlying timing resolution of $4 \mu \mathrm{s}$. All programs for data analysis were written in the Spike2 script language.

CBCTO stimulation. The distal end of the CBCTO was attached to an electromechanical puller consisting of a 5 inch mid-range speaker with an optical position sensor controlled by a proportional-integrodifferential (PID) controller (Hofmann and Koch, 1985) operating in length-feedback mode. The frequency response of this puller is flat to a bandwidth of $220 \mathrm{~Hz}$ over a length range of $\pm 0.8 \mathrm{~mm}$ (Fig. $1 \mathrm{~B}$ ). The 
CBCTO was driven with band-limited Gaussian white noise generated by a 32-bit pseudorandom number generator clocked at $10 \mathrm{kHz}$. The binary output was filtered to the desired bandwidth with a variable eight-pole active filter [Wavetek 852 (San Diego, CA)] and amplified and offset as desired using custom-built amplifiers. Trapezoidal waveforms for identification of single afferent response characteristics were generated by a custom-built function generator with variable duration and rise/fall time.

Data analysis and statistics. The precision of the spike timing of GPR2 and CBCTO afferents was evaluated by calculating the jitter in the timing of individual spikes produced by each receptor in response to multiple presentations of the same stimulus. The data acquisition protocols were very similar for the two preparations; the slight differences between them are explained in the following paragraphs. In each case, the receptor was stimulated with a short-duration random-movement sequence that was repeated for at least 100 cycles or "trials." A minimum of 50 cycles of the response was used to construct a peristimulus time histogram (PSTH) of the afferent spike trains. The cycles that were used in the analysis were taken from the end of the total stimulus period, after slow spike rate adaptation had concluded and the mean afferent firing rate had stabilized. The PSTH was examined and "events" were identified as features in the stimulus that dependably (in at least $20 \%$ of the GPR 2 and at least $30 \%$ of the CBCTO trials) evoked a spike in each response cycle. In other words, events corresponded to vertical columns of spikes in the spike time raster plots. For each of these events, the times of the associated spikes referenced to the start of a cycle were extracted from the raw data file. The SD of the individual spike times at each event was defined as the jitter of the event. For each event, we defined its reliability as the fraction of the trials in which a spike was elicited. (Thus, reliability varied from 0.2 to 1 for each GPR2 event and from 0.3 to 1 for each CBCTO event.) Because there was no strong correlation between the jitter and reliability of an event (see Figs. $2 E, 3 F, 4 F$ ), the analysis of jitter was not sensitive to the particular choice of the threshold reliability.

The details of the procedures used to identify events differed slightly for the two preparations. For the GPR2 experiments, the stimulus was $6 \mathrm{~s}$ of movement generated by $20 \mathrm{~Hz}$ bandwidth white noise, preceded and followed by $1 \mathrm{~s}$ without stretch, for a total sweep duration of $8 \mathrm{~s}$. This was repeated 100 times, and the PSTH was constructed from the last 50 cycles of stimulation. To detect events, we applied a threshold with a narrow bin width ( $4 \%$ threshold with $0.5 \mathrm{~ms}$ bins) to the PSTH. We found the start and end times of each candidate event by moving backward and forward in time until an empty bin was found. The number of spikes in this portion of the PSTH was divided by the number of trials and, if $>0.2$, was given further consideration. We observed that, on average, GPR2 events included more than one spike in $1-2 \%$ of the trials. Of the 2786 control spikes that were in events, 54 were doublets and one was a triplet. The 3430 AST event spikes included 47 doublets and two triplets. For event identification and jitter analysis, only the first spike of a doublet or triplet was used and any following spikes were discarded. In a few instances, we observed two events that could not be separated, and we removed these from our analysis by eliminating events where the total number of spikes divided by the number of trials was $>1.2$. The extra $20 \%$ allowed for the inclusion of occasional doublets.

For the CBCTO experiments, the stimulus was a 5 s sequence of $140 \mathrm{~Hz}$ bandwidth white noise that was repeated 100-120 times with no pause between stimulus cycles. The identification of events with reliability $>0.3$ was accomplished by applying a threshold to the PSTH plot ( $1 \mathrm{~ms}$ bins) that was in the range of 7-10 spikes. Data was extracted by searching for spikes within $3.5 \mathrm{~ms}$ of this time. The minimum interspike interval measured for CBCTO spikes trains evoked by $140 \mathrm{~Hz}$ noise was 5-6 ms and, unlike in GPR2, spike doublets were never observed.

In both the GPR2 and CBCTO experiments, the same stimulus waveform was used under both control and modulated conditions. To determine whether neuromodulation significantly changed the jitter in a given experiment, paired $t$ tests were used to compare the jitter of events under the two conditions. For all statistical tests, significance with respect to control was indicated on figures using the following symbols: ${ }^{\star} p<0.05$; ${ }^{* *} p<0.01 ;{ }^{* *} p<0.001$. Error bars correspond to SEs on plots in Figures $2-4$ and SDs on plots in Figure 6 . The total number of experi- ments using a particular protocol is indicated by " $N$," whereas the total number of events in an individual experiment is indicated by " $n$."

\section{Results}

\section{GPR2 spike rate and jitter decrease in AST}

The GPR2 neuron provides sensory feedback to the crustacean stomatogastric ganglion (Katz et al., 1989; Katz and HarrisWarrick, 1989, 1990, 1991; Blitz et al., 2004; Beenhakker et al., 2005). GPR 2 dendrites ramify across the cpv3a and gm 9 muscles, and stretch of either muscle elicits GPR2 neuron action potentials that can be recorded extracellularly (Fig. 1A) in the gastropyloric nerve ( $g p n)$. In a previous study, we found that the GPR2 spike rate in response to sustained stretch of cpv3a decreased in the presence of micromolar concentrations of the peptide AST (Birmingham et al., 2003). This peptide circulates in the crab's hemolymph as a neurohormone (Li et al., 2003; Billimoria et al., 2005), and AST immunoreactivity has also been shown in the GPR2 neuron itself (Skiebe and Schneider, 1994).

To investigate the effect of AST on the precision of spike timing in response to a time-varying stimulus, we did a series of experiments in which we used 100 trials of a $20 \mathrm{~Hz}$ low-passfiltered white noise waveform, $6 \mathrm{~s}$ in duration, with $2 \mathrm{~s}$ pauses between repeated stimulus presentations. For this stimulus, which varies rapidly compared with the GPR2 interspike interval, GPR2 encodes the stimulus in the spike times rather than in the average spike rate. The top traces of Figure $2 A$ are representative extracellular recordings of spikes in response to the stimulus shown directly below. Rasters showing the last 50 responses and summary PSTHs are shown below the stimulus. The spontaneous activity of GPR2 and the stimulus-evoked spike rate both decreased in the presence of $10^{-6} \mathrm{M}$ AST, and events are indicated $(+)$. Figure $2 \mathrm{~B}$ plots the differences between the times of individual spikes and the average time of the associated event for all spikes in nine experiments ( 50 trials each) and shows that the spike timing was more precise in the peptide. The inset in Figure $2 B$ plots the spike time differences over all trials in control and AST for a single event (\#) in the experiment shown in Figure $2 \mathrm{~A}$. As defined in the Materials and Methods section, the spiketiming jitter is the SD of individual timing differences averaged over all spikes. For the experiment shown in Figure $2 \mathrm{~A}$, the jitter averaged over all events was $1.37 \mathrm{~ms}$ under control conditions and in $1.17 \mathrm{~ms}$ in AST. Figure $2 C$ shows that over nine experiments, the average jitter decreased significantly from $1.93 \mathrm{~ms}$ in control to $1.32 \mathrm{~ms}$ in AST (paired $t$ test, $p=0.009$ ). In these same experiments, AST also significantly decreased the average spike rate (Fig. $2 D)$ during the stimulus $(N=9$; paired $t$ test, $p=0.013)$ but did not cause a significant change in the average reliability $(N=9$; paired $t$ test, $p=0.631$; data not shown). We found that, when considering all control and AST events in all experiments (Fig. 2E), there was not a significant correlation between the jitter of an event and its reliability $(n=209$; $C C=0.0878 ; p=0.205)$. Because the correlation coefficient was not negative, the decrease in jitter in AST cannot be attributed to the elimination of less reliable, higher jitter events from the data set. However, Figure $2 \mathrm{~F}$ shows that for these nine experiments there was a significant positive correlation between jitter and mean firing rate $(\mathrm{CC}=$ 0.838; $p<0.001)$ under both control and AST modulated conditions. In this calculation, the control and modulated data were pooled. Positive correlations were also found when the data corresponding to each condition were considered separately (control: $\mathrm{CC}=0.806, p=0.009$; AST: $\mathrm{CC}=0.664, p=0.05)$. Given the positive correlation between jitter and firing rate, we cannot 
A
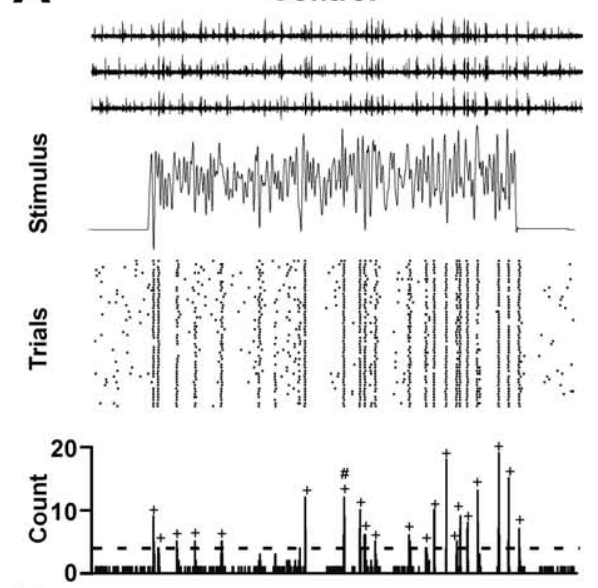

B

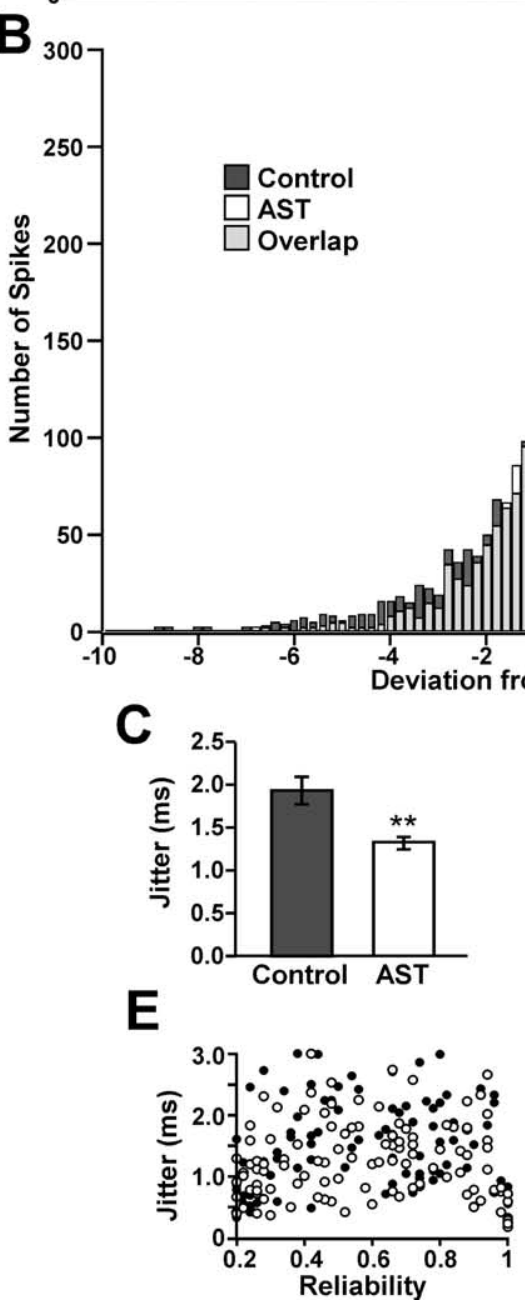

Allatostatin
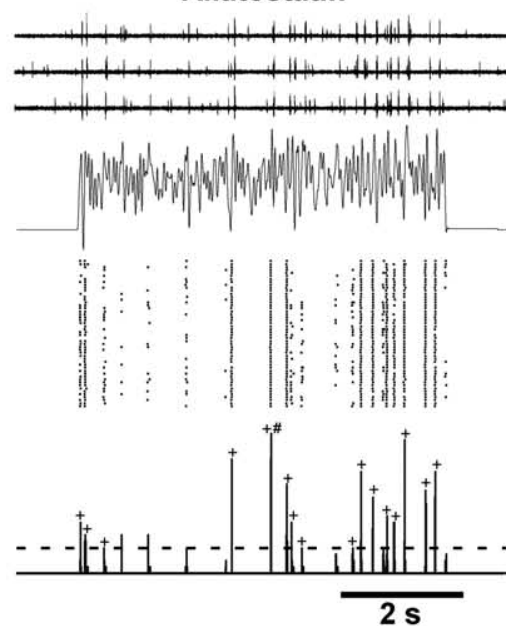

conclude that the reduction in jitter attributable to the action of AST is independent of the decrease in firing rate.

\section{CBCTO spike rate and jitter decrease in AST}

We made a parallel study of the effects of AST on spike-timing precision in another invertebrate mechanoreceptor preparation, the CBCTO of the shore crab C. maenas (Fig. $1 B$ ). The CBCTO is a typical crustacean chordotonal organ (Mill, 1976) that spans the CB leg joint and mediates classic negative feedback reflexes at the $\mathrm{CB}$ joint (Bush, 1965). The $\sim 80$ CBCTO afferents are directionally sensitive and individual cells respond to either stretch or release of the receptor corresponding to depression or levation of the CB joint (Bush, 1965). CBCTO afferents, unlike GPR2 neurons, can easily be studied intracellularly (DiCaprio, 2003; Gamble and DiCaprio, 2003). As in C. borealis, peptides belonging to the allatostatin superfamily have also been found in the CNS of C. maenas (Duve et al., 1997).

Figure $3 A$ shows a $100 \mathrm{~ms}$ segment of intracellular recording from a single CBCTO afferent in control saline and in $10^{-6} \mathrm{M}$ AST in response to a single cycle of repeated stimulation using a $5 \mathrm{~s}$ duration $140 \mathrm{~Hz}$ bandwidth white noise stimulus, along with raster plots of the last 60 stimulus trials and associated PSTHs. Figure $3 B$ plots the individual differences from the mean spike time in control and AST for all of the events in the experiment shown in Figure $3 A$. The inset shows the time differences for a single stimulus event (\#) in that experiment. The jitter for this single event decreased from 0.50 to $0.35 \mathrm{~ms}$ after application of AST. When considering all events in this experiment (Fig. 3C), AST application resulted in a significant decrease in jitter from $0.394 \pm 0.007$ to $0.343 \pm 0.006 \mathrm{~ms}(n=118$; paired $t$ test, $p<0.001)$. Although the effects of AST on CBCTO jitter and mean firing rate over all experiments were less dramatic than what had been seen with GPR2 neurons, the decrease in the average CBCTO jitter in AST (Fig. $3 D)$ was statistically significant $(N=$ 28; paired $t$ test, $p<0.001$ ), as was the decrease in average spike rate in AST (Fig. 3) $(N=28$; Wilcoxon signed rank test, $p=$ $0.024)$. In the latter case, a paired $t$ test was inappropriate because the data were not normally distributed $(p<0.001)$. As with GPR2, we found no significant correlation between jitter and reliability in the CBCTO experiments (Fig. $3 F$ ) when considering all events $(n=3877$; $\mathrm{CC}=$ $-0.0222 ; p=0.166)$, and the presence of 
AST did not result in a significant change in average reliability $(N=28 ; p=0.484$, paired $t$ test; data not shown).

\section{CBCTO spike rate and jitter increase in serotonin}

The presence of serotonin affects the sensitivity of a number of crustacean stretchsensitive neurons (Pasztor and Bush, 1987; Strawn et al., 2000) including GPR2 (Birmingham et al., 2003). In the last case serotonin, like AST, decreases the spike rate (Birmingham et al., 2003). In contrast, serotonin increases the static and dynamic response of crustacean chordotonal afferents (el Manira et al., 1991; Rossi-Durand, 1993) in a dosedependent manner and also increases the input resistance of leg motor neurons that receive input from chordotonal afferents (Le Bon-Jego et al., 2004). We repeated the CBCTO experimental protocol described above to test whether serotonin also modified the spike-timing precision. Figure $4 \mathrm{~A}$ shows a $200 \mathrm{~ms}$ portion of an intracellular recording from a single CBCTO afferent in control saline and in $10^{-6} \mathrm{M}$ serotonin in response to repeated stimulation with a $5 \mathrm{~s}$ duration $140 \mathrm{~Hz}$ bandwidth white noise stimulus along with raster plots of the last 70 stimulus cycles and the PSTHs. Figure $4 B$ plots the individual differences from the mean spike time in control and serotonin for all of the events in the experiment shown in Figure $4 A$. The jitter for the single stimulusevoked event (\#) increased from 0.50 to 0.72 ms after application of serotonin (Fig. $4 B$, inset). When considering all events in this experiment, serotonin application resulted in a significant increase in mean jitter from $0.593 \pm 0.018$ to $0.655 \pm 0.020 \mathrm{~ms}$ (Fig. $4 C$ ) ( $n=87 ; p<0.001$, paired $t$ test). Over all experiments, the increases in both the average CBCTO afferent jitter (Fig. $4 D$ ) and the mean spike rate (Fig. $4 E$ ) in serotonin were significant $(N=9$; paired $t$ test, $p<0.001$, $p=0.0016$, respectively), but no significant change in reliability was observed $(N=9$; $p=0.230$, paired $t$ test; data not shown). A small but statistically significant negative correlation between reliability and jitter was seen (Fig. $4 F$ ) when considering all events in all experiments $(n=2714$; CC $=-0.0392$; $p=0.031)$.

\section{Neuromodulatory effects on jitter in CBCTO are not mediated by effects on rate}

As with GPR2, the neuromodulatory effects on jitter for CBCTO afferents were always accompanied by changes in the mean firing rate. To determine whether the change in jitter might be explained entirely in terms of a change in firing rate, we
A

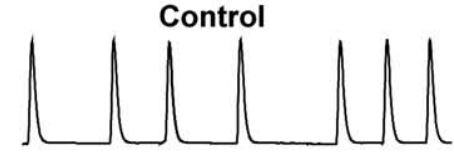

के
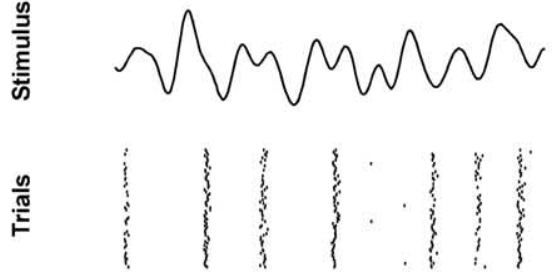

$\overbrace{0}^{50} 25-\mid$

B
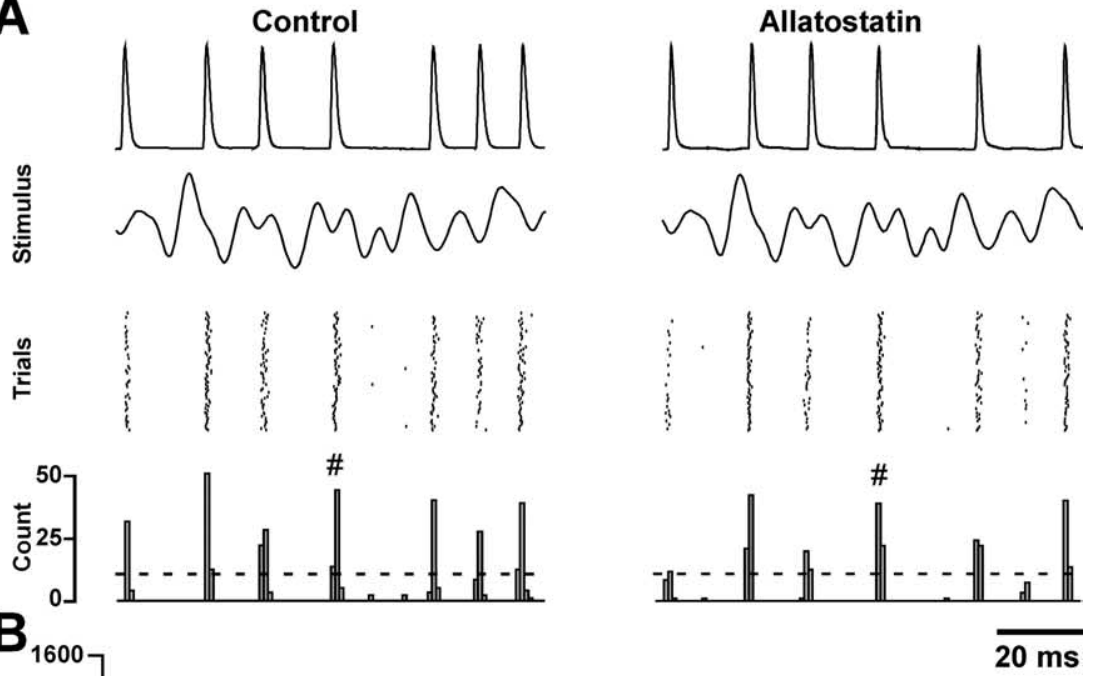
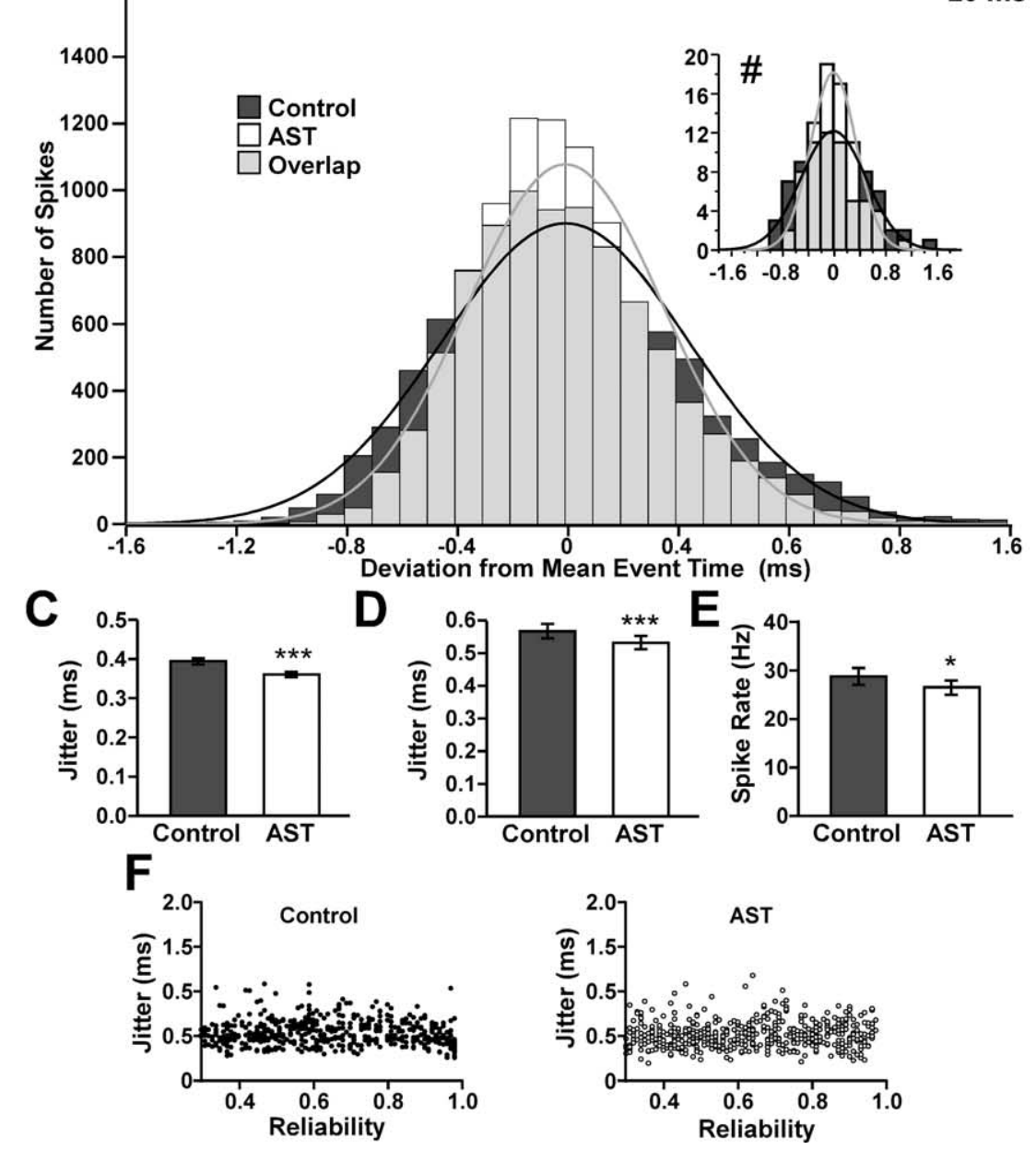

Figure 3. In the CВCTO afferent of C. maenas, allatostatin causes a decrease in spike rate and a decrease in spike-timing jitter in response to a constantly varying stimulus. $A, A 100 \mathrm{~ms}$ segment of the intracellular recording, stimulus, spike time raster, and PSTH for 60 repetitions of a $5 \mathrm{~s}$ duration, $140 \mathrm{~Hz}$ low-pass-filtered white noise stretch in control saline (left) and in $10^{-6} \mathrm{M}$ AST (right). The dashed line denotes event threshold. $\boldsymbol{B}$, Histogram of deviations of individual spike times from the average spike time for all matched events $(n=118$ ) in this experiment under both control and AST modulated conditions. Overlap between the two distributions is shown in gray. In this experiment, a total of 10,132 event spikes were measured under control conditions, whereas 9603 were measured in AST. Inset, Histogram for a single event marked \# in $\boldsymbol{A}$. The black and gray curves are Gaussian fits to the control and AST data, respectively. $\boldsymbol{C}$, Effect of $10^{-6}$ M AST on the spike-timing jitter in the experiment shown in $\boldsymbol{A}(p<0.001$; $n=118)$. $\boldsymbol{D}$, Effect of $10^{-6} \mathrm{M}$ AST on CBCTO spike-timing jitter in 28 chordotonal afferents $(p<0.001)$. $\boldsymbol{E}$, Effect of $10^{-6} \mathrm{M}$ AST on spike rate ( $p=0.024 ; N=28$ ). $\boldsymbol{F}$, Jitter plotted against reliability for 500 control and 500 AST events randomly selected from all of the events (2003 control; 1874 AST) measured in 28 experiments. Plotting all events would have resulted in overlapping points that would have obscured the structure of the distribution of data. There is no significant correlation between jitter and reliability when considering all events in all experiments $(n=3877 ; C C=-0.0222 ; p=0.166)$. 
A
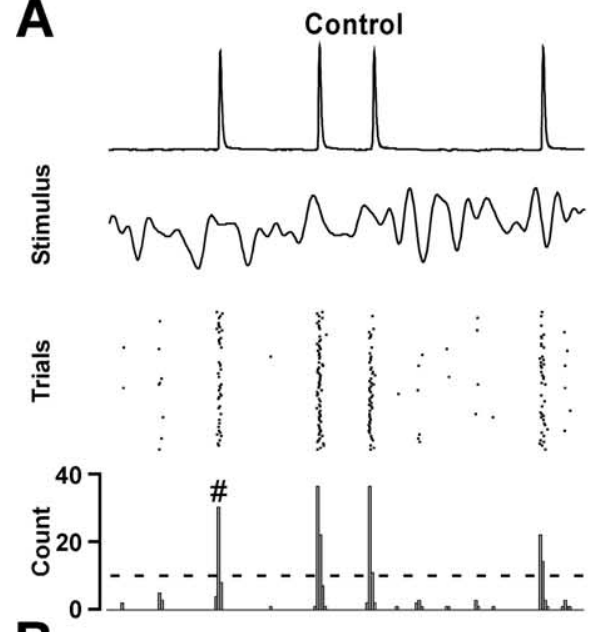

B
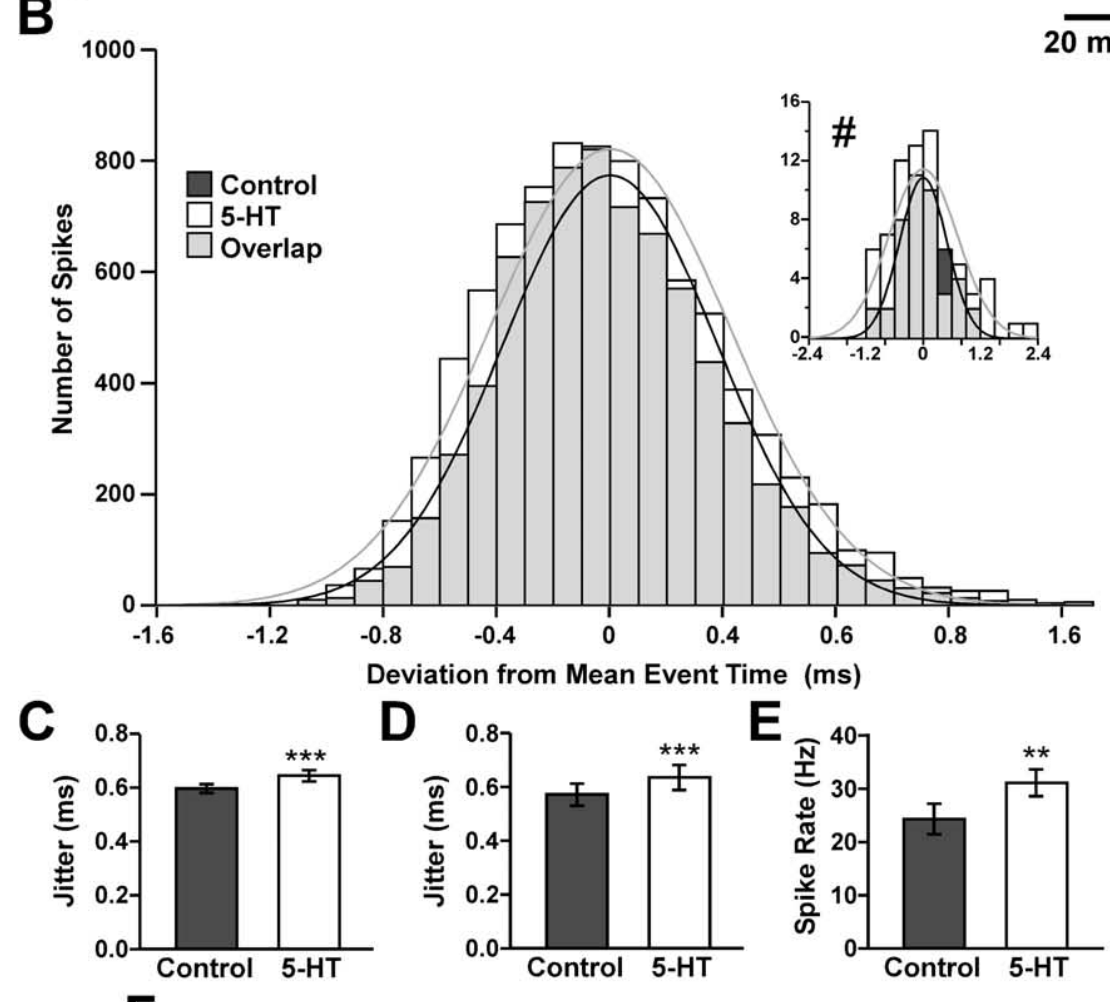

D
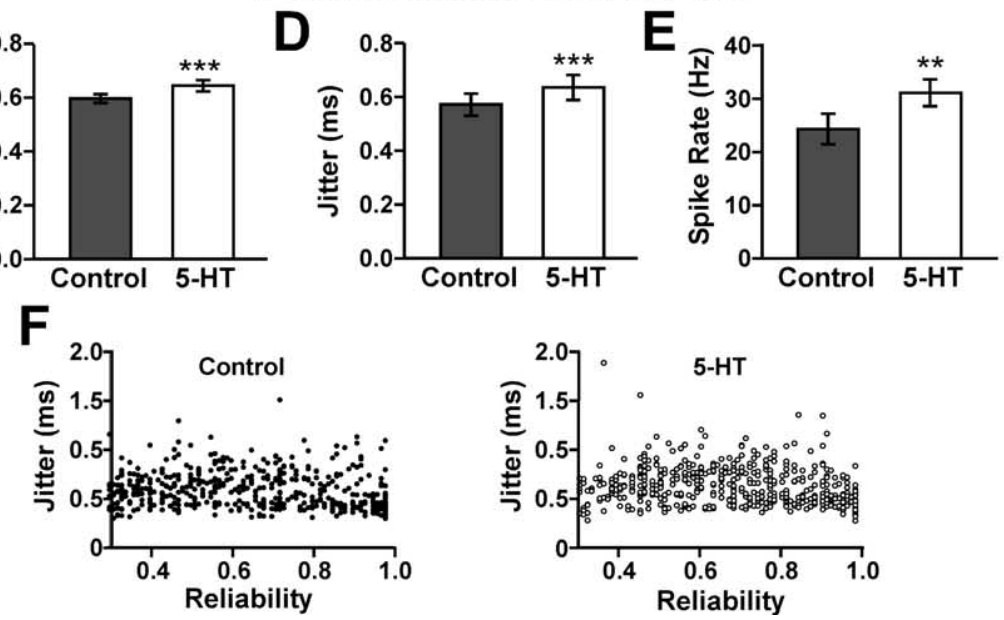

Figure 4. Serotonin causes an increase in spike jitter and mean spike rate in response to a constantly varying stimulus in the CBCTO. A, A 200 ms segment of the intracellular recordings, stimulus, spike time raster, and PSTH for 70 repetitions of a $5 \mathrm{~s}$ duration, $140 \mathrm{~Hz}$ low-pass-filtered white noise stimulus in control saline (left) and in $10^{-6} \mathrm{M}$ serotonin (right). Dashed line denotes event threshold. $\boldsymbol{B}$, Histogram of deviations of individual spike times from the average spike time for all matched events $(n=87)$ in this experiment under both control and serotonin-modulated conditions. Overlap between the two distributions is shown in gray. In this experiment, a total of 7327 event spikes were measured under control conditions, whereas 8728 were measured in serotonin. Inset, Histogram for a single event marked \# in $\boldsymbol{A}$. The black and gray curves are Gaussian fits to the control and serotonin data, respectively. $\boldsymbol{C}$, Effect of $10^{-6} \mathrm{M}$ serotonin on the spike-timing jitter in the experiment shown in $\boldsymbol{A}$ ( $p<$ $0.001 ; n=87)$. $\boldsymbol{D}$, Effect of $10^{-6} \mathrm{M}$ serotonin on (BCT0 spike-timing jitter in nine chordotonal afferents $(p<0.001)$. $\boldsymbol{E}$, Effect of $10^{-6}$ M serotonin on spike rate $(p=0.0016 ; N=9)$. $\boldsymbol{F}$, Jitter plotted against reliability for 500 control and 500 serotonin events randomly selected from all of the events (1322 control; 1392 serotonin) measured in nine experiments. A small but statistically significant negative correlation between reliability and jitter is obtained when considering all events in all experiments $(n=$ 2714; $C C=-0.0392 ; p=0.031)$. examined the relationship between the CBCTO afferent mean firing rate and jitter under both control and modulated conditions for the experiments described in Figures 3 and 4. In Figure 5, $A$ and $B$, jitter is plotted against mean spike rate for each experiment in control (filled circles) and modulator (AST or serotonin, open circles). There was a significant negative correlation between jitter and mean firing rate $(\mathrm{CC}=-0.369 ; p=0.005)$ for the AST experiments, although there was no significant correlation between jitter and mean rate for the set of serotonin experiments $(\mathrm{CC}=-0.201 ; p=0.423)$. Control and modulator data were pooled for these calculations. The lack of positive correlations between mean firing rate and jitter for CBCTO afferents indicates that the effects on jitter do not result simply from the changes in mean firing rate.

AST and serotonin modify the CBCTO somatic current-voltage relationship Neuromodulation of a sensory neuron often occurs in one of two ways. First, the conductance(s) associated with the transduction mechanism itself could be modulated. Alternatively, other conductances associated with the cell's excitability could be modified. In the latter case, changes in the steady-state current-voltage relationship of the neuron would be expected if the currents affected have a persistent component. To construct CBCTO I-V curves, we did experiments in current-clamp mode in the presence of $2 \times 10^{-7} \mathrm{M}$ TTX to block action potentials. Figure $6 \mathrm{~A}$ shows a family of voltage responses to current injections in TTX saline and in TTX saline containing $10^{-6} \mathrm{M}$ AST for one experiment, and Figure $6 B$ plots the current-voltage relationship corresponding to the steadystate portions of the curves. The slope of the $I-V$ relationship decreased in the presence of AST, and the two $I-V$ curves intersect at $-76 \mathrm{mV}$, the reversal potential for the affected conductance. Over four experiments, application of AST significantly decreased the slope of the $I-V$ curve measured in the linear range between -80 and $-60 \mathrm{mV}$ from $15.8 \pm 0.8$ to $10.8 \pm 1.0$ $\mathrm{mV} / \mathrm{nA}$ (paired $t$ test, $p=0.042$ ). Figure 6, $C$ and $D$, shows that the presence of $10^{-6} \mathrm{M}$ serotonin had the opposite effect of AST, increasing the slope of the $I-V$ curve. Over three experiments, application of serotonin significantly increased the average slope over the same voltage range from $19.6 \pm 1.7$ to $27.8 \pm 2.0 \mathrm{mV} / \mathrm{nA}$ (paired $t$ test, $p=0.031$ ).

Two comments should be made about the current injection experiments and the 


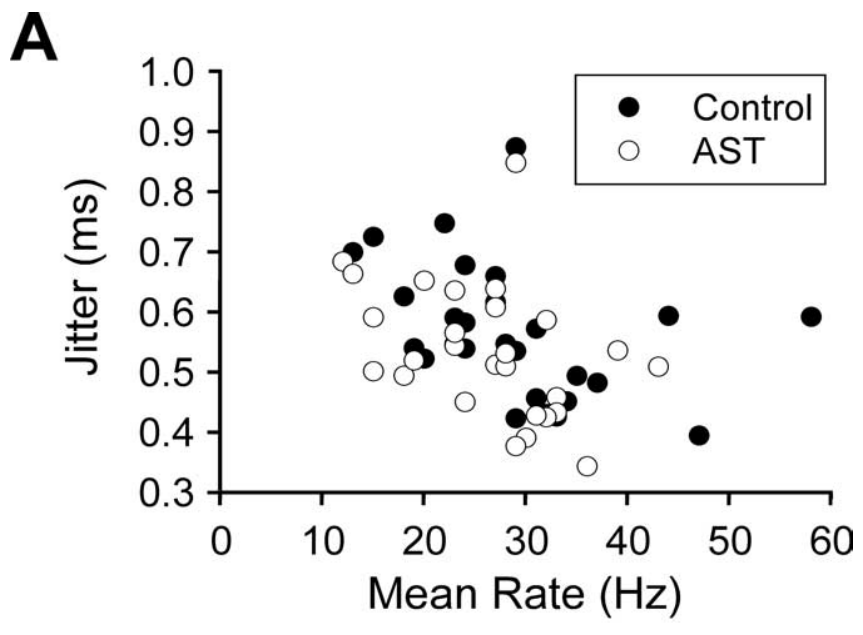

B

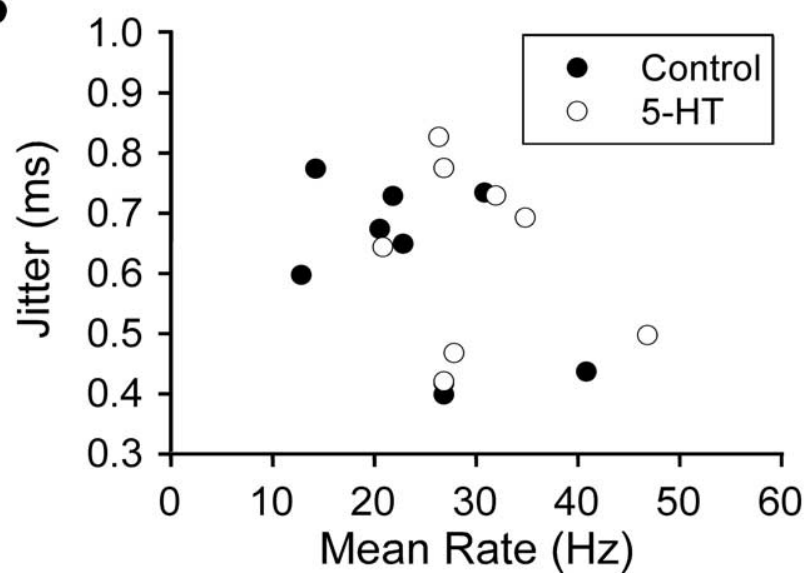

Figure 5. The lack of positive correlations between jitter and mean firing rate for the CBCTO afferents indicates that effects on jitter are not mediated by effects on rate. $A$, Mean jitter plotted against mean spike rate for each (BCTO experiment in control (filled circles) and AST (open circles). There is a significant negative correlation between jitter and mean rate $(C \mathrm{C}=$ $-0.369 ; p=0.005) . B$, Mean jitter plotted against mean spike rate for each CBCT0 experiment in control (filled circles) and serotonin (5-HT; open circles). There is no significant correlation between $j$ itter and rate $(C C=-0.201 ; p=0.423)$.

derived $I-V$ relationships. First, the steady-state $I-V$ curves, even under control conditions, varied in shape (Fig. $6 B, D$ ). This is not surprising given that each of the seven experiments (four AST, three serotonin) was made using an unidentified CBCTO cell, of which 10-12 are accessible in each preparation. Second, application of each neuromodulator may induce effects more complicated than simple modifications of the cell's steady-state properties. Neuromodulation may also modify transient currents either directly and/or indirectly through effects on excitability and membrane resistance. For example, a transient outward current is apparent in the most hyperpolarized trace in Figure $6 C$ in serotonin but not under control conditions. Although these more complicated effects of neuromodulation may play roles in CBCTO spiking, we have focused on steady-state properties because, for the physiologically relevant range between -110 and $-40 \mathrm{mV}$, very little transient current was measured. Moreover, the modification of the slope of the $I-V$ curve described in the previous paragraph was the only modulator-induced effect seen consistently from experiment to experiment.
A

A TTX

$\mathrm{AST}+\mathrm{TTX}$
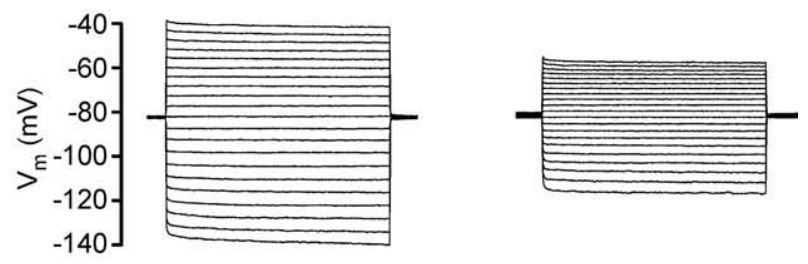

B

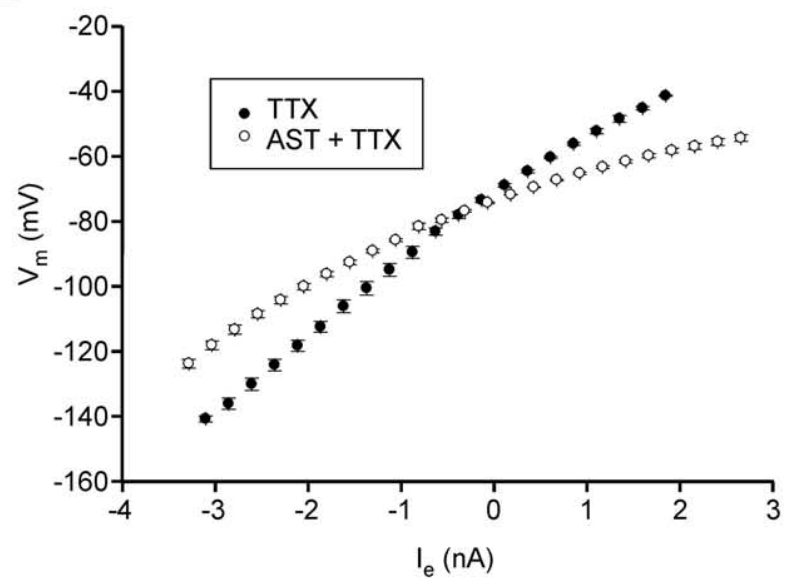

C
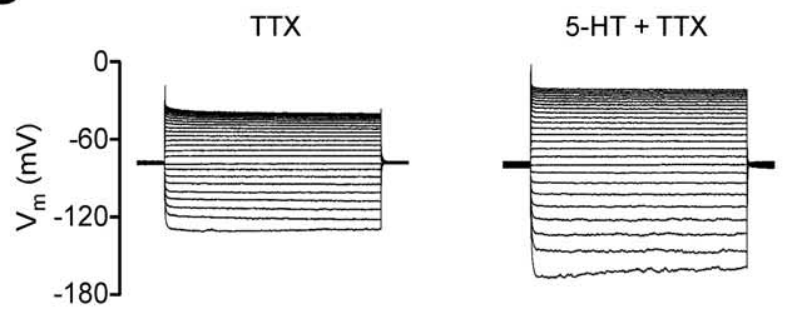

D

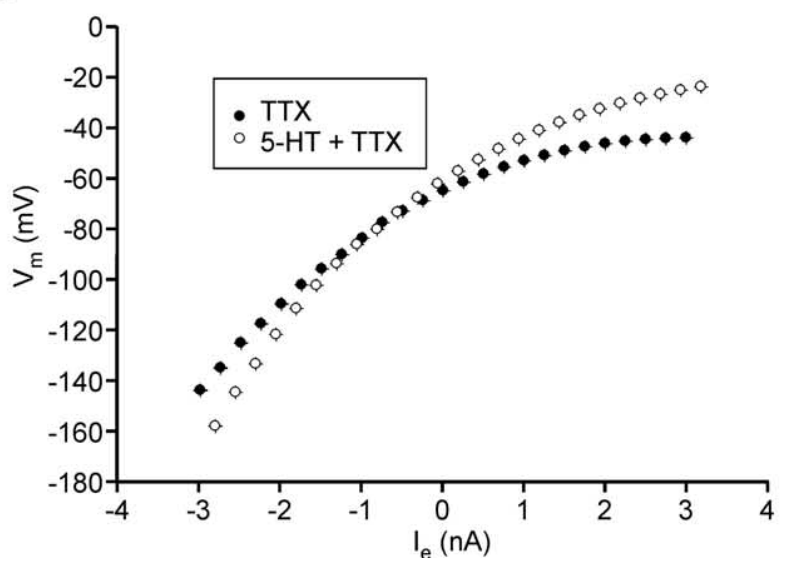

Figure 6. Allatostatin induces a conductance increase and serotonin induces a conductance decrease in the chordotonal afferents. $A$, Current-clamp recording of a CBCTO afferent voltage $\left(V_{\mathrm{m}}\right)$ in response to injected current $\left(I_{\mathrm{e}}\right)$ in the presence of $2 \times 10^{-7} \mathrm{M} \mathrm{TTX}($ left $)$ and in TTX and $10^{-6} \mathrm{M}$ AST (right). $\boldsymbol{B}$, Steady state $I-V$ curve showing decrease in membrane resistance (slope) in the presence of AST. C, Current-clamp recording of a CBCTO afferent voltage in response to injected current in the presence of $2 \times 10^{-7} \mathrm{M}$ TTX (left) and in TTX and $10^{-6} \mathrm{M}$ serotonin (5-HT; right). D, Steady-state $I-V$ curve showing an increase in membrane resistance (slope) in the presence of serotonin. Each $I--V$ curve was measured three times under each condition; the error bars correspond to SDs in the voltage measured for each current injection. 


\section{Paired axonal and soma-axon recordings show extremely precise timing}

To determine whether axonal conduction contributed to the observed jitter in CBCTO afferents, we made paired axonal recordings from the same afferent at two positions in the axon (7-9 $\mathrm{mm}$ electrode spacing). Spikes were evoked by random $(140 \mathrm{~Hz}$ white noise) movement of the CBCTO, and the jitter introduced by propagation was calculated as the SD of the time interval between spikes at the two recording sites. The average jitter over four experiments was $7.93 \pm 1.07 \mu$ s (data not shown), indicating that spike propagation contributes negligibly to the total jitter described in Figures 3 and 4 . We also made paired recordings in four preparations from the soma and axon of single CBCTO afferents. In these experiments, it was not possible to mechanically stimulate the CBCTO without disturbing the electrode in the soma, and so spikes were evoked by intracellular injection of sinusoidal or $140 \mathrm{~Hz}$ bandwidth white noise current into the soma. As with the dual axon recordings, the jitter in the mean latency between spikes recorded in the soma and axon was very small $(<30 \mu \mathrm{s})$, although the mean jitter in the timing of individual spikes evoked by the current stimulus was $0.105 \pm 0.020 \mathrm{~ms}(N=4$; data not shown). This is smaller than the mean jitter of $0.57 \mathrm{~ms}$ in spikes evoked by mechanical stimulation, indicating that spike initiation is only one factor contributing to the overall jitter.

The fidelity of the movement transducer used to stimulate the CBCTO was assessed by applying a threshold to the movement monitor of the feedback system controlling the puller and calculating the jitter of these pseudo events. In all experiments, the jitter in the movement system ranged from 4 to $6 \mu$ s, which is close to the maximum timing resolution of the analog-to-digital converter in the CED data acquisition system. This indicates that the mechanical instability of the transducer and puller were not important sources of temporal jitter.

\section{Discussion}

In this study, we demonstrated that the temporal precision of spike trains generated by two different crustacean stretchsensitive neurons is comparable with that of the most reliable neurons in any vertebrate or invertebrate nervous system. To the best of our knowledge, this is the first investigation examining neuromodulation of temporal jitter in a primary sensory neuron. Previous studies of invertebrate mechanoreceptors have shown that neuromodulation can modify neuronal firing properties (Pasztor and Bush, 1987, 1989; el Manira et al., 1991; RossiDurand, 1993; Strawn et al., 2000; Birmingham, 2001) including the firing rate (Birmingham et al., 2003), sensitivity (Widmer et al., 2005), kinetics of adaptation (Zhang et al., 1992; Birmingham et al., 2003), tonic versus phasic response, (Ramirez et al., 1993; Matheson, 1997), and even the mode of firing (Combes et al., 1997). In this study, we show for the first time that neuromodulators can also modify the temporal precision of spike trains produced in these neurons.

\section{Sources of jitter in the CBCTO system}

The major source of neuronal noise is thought to be the probabilistic nature of ion channel openings and closings (Schneidman et al., 1998; White et al., 1998, 2000; Steinmetz et al., 2000; Diba et al., 2004; Jacobson et al., 2005). These can result in variability in cellular excitability, synaptic release, spike propagation velocity, the timing of synaptic inputs (Maršálek et al., 1997), and in the case of primary afferents, sensory transduction. For sensory neurons, or at least those in the visual system, noise in the stimulus itself may possibly also affect the reliability of the neural response
(Borst and Haag, 2001; Lewen et al., 2001; Grewe et al., 2003), although we determined that this is not an issue in the CBCTO experiments. Our paired axonal and soma-axon recordings also ruled out spike propagation as contributing appreciable jitter to the spike trains. Thus, in the CBCTO system we conclude that the jitter must originate in the biomechanical properties of the receptor, the mechanotransduction process, and/or channel noise in the soma-dendrite compartment.

\section{Biophysical mechanism responsible for jitter modification}

The jitter in a spike train is not only a property of the neuron; it also depends on the stimulus. Rapidly varying, large amplitude stimuli should produce less jitter than stimuli that slowly and barely reach threshold. Most previous studies of precise spiking have focused on the dependence of precision on features (amplitude, frequency, contrast, and velocity) of the stimulus (Mainen and Sejnowski, 1995; Berry et al., 1997; Nowak et al., 1997; Hunter et al., 1998; Cecchi et al., 2000; Beierholm et al., 2001; Fellous et al., 2001; Hunter and Milton, 2003; Diba et al., 2004; Szücs et al., 2004). In our investigations we manipulated not stimulus parameters, but rather properties of the neurons themselves through the application of neuromodulators. Of more direct relevance to our work are an investigation of the effects of BDNF on spike jitter in cultured hippocampal cells (Fujisawa et al., 2004) and studies in Aplysia (Szücs et al., 2004) and the prefrontal cortex (Schreiber et al., 2004) using the dynamic-clamp technique (Sharp et al., 1993; Prinz et al., 2004). In all three cases, jitter decreased with increased conductance. Our CBCTO results similarly showed that AST increased the membrane conductance of the stretch receptors and that this was accompanied by a decrease in jitter. In contrast, serotonin decreased conductance but increased the jitter. Although the effects of each modulator are likely more complicated, the correlated changes of rate and jitter we observed could result from modulation of a single channel type. The measured $I-V$ relationships show that neither neuromodulator induced a large shift in the membrane resting potential. This suggests that one major effect of each substance is simply to change the membrane resistance, perhaps through modification of $\mathrm{a} \mathrm{Cl}^{-}$conductance. Assuming that the modulators do not affect the transduction channels and the overall transduction current, a decreased membrane resistance in the presence of AST would lower the firing rate by reducing the receptor potential. In addition, the decreased membrane resistance would also decrease the integration time, resulting in increased sensitivity to faster transients in the stimulus, which could bring about better defined threshold crossings and decreased jitter. Increased membrane resistance in serotonin would have the opposite effect on the receptor potential and membrane potential noise, producing an increase in firing rate and jitter. What we can say with some certainty is that the change in temporal jitter in the CBCTO system induced by either neuromodulator does not result solely from a modification of the firing rate. Previous work in neocortex suggested that there is a strong positive correlation between jitter and spike rate (Tang et al., 1999). Whereas we saw exactly this correlation in the control data for the GPR2 neurons, the reverse was true for the CBCTO neurons. From this we conclude that the relationship between jitter and spike rate may depend on the ion channel composition in an individual neuron, and there may be no general relationship that holds for all neurons.

Functional significance of neuromodulatory effects on jitter Naively, one might expect that the reduction of the firing rate of a sensory neuron via some biophysical mechanism would result 
in a decrease in performance. Our results, however, show that this is not necessarily true when the decrease in firing is accompanied by increased precision in the timing of each individual spike. Whether reduced jitter in the spiking of a neuron has functional significance will depend on the time scale over which input is integrated by cells postsynaptic to that neuron. In particular, if the membrane time constant of the postsynaptic neuron is relatively small, and if the postsynaptic neuron is integrating inputs from multiple presynaptic neurons, the modulation of jitter could be very important for the temporal integration of information. However, if the membrane time constant of the postsynaptic neuron is relatively long, small changes in jitter may be less crucial. If neuromodulation results in additional changes to the spiking properties of a neuron in addition to modifying the jitter, the effect on coding fidelity will undoubtedly be more complicated. Nonetheless, we show that jitter, like many other properties important for circuit dynamics, is subject to modulation.

\section{References}

Adrian E, Zotterman Y (1926) The impulses produced by sensory nerve endings. II. The responses of a single end-organ. J Physiol (Lond) 61:151-171.

Aldworth ZN, Miller JP, Gedeon T, Cummins GI, Dimitrov AG (2005) Dejittered spike-conditioned stimulus waveforms yield improved estimates of neuronal feature selectivity and spike-timing precision of sensory interneurons. J Neurosci 25:5323-5332.

Barlow HB (1963) The information capacity of nervous transmission. Kybernetik 187:15-28.

Beenhakker MP, DeLong ND, Saideman SR, Nadim F, Nusbaum MP (2005) Proprioceptor regulation of motor circuit activity by presynaptic inhibition of a modulatory projection neuron. J Neurosci 25:8794-8806.

Beierholm U, Nielsen CD, Ryge J, Alstrom P, Kiehn O (2001) Characterization of reliability of spike timing in spinal interneurons during oscillating inputs. J Neurophysiol 86:1858-1868.

Berry MJ, Meister M (1998) Refractoriness and neural precision. J Neurosci 18:2200-2211.

Berry MJ, Warland DK, Meister M (1997) The structure and precision of retinal spike trains. Proc Natl Acad Sci USA 94:5411-5416.

Bialek W, Rieke F (1992) Reliability and information transmission in spiking neurons. Trends Neurosci 15:428-434.

Bialek W, Rieke F, de Ruyter van Steveninck RR, Warland D (1991) Reading a neural code. Science 252:1854-1857.

Billimoria CP, Li L, Marder E (2005) Profiling of neuropeptides released at the stomatogastric ganglion of the crab, Cancer borealis with mass spectrometry. J Neurochem 95:191-199.

Birmingham JT (2001) Increasing sensor flexibility through neuromodulation. Biol Bull 200:206-210.

Birmingham JT, Szuts ZB, Abbott LF, Marder E (1999) Encoding of muscle movement on two time scales by a sensory neuron that switches between spiking and bursting modes. J Neurophysiol 82:2786-2797.

Birmingham JT, Billimoria CP, DeKlotz TR, Stewart RA, Marder E (2003) Differential and history-dependent modulation of a stretch receptor in the stomatogastric system of the crab, Cancer borealis. J Neurophysiol 90:3608-3616.

Blitz DM, Beenhakker MP, Nusbaum MP (2004) Different sensory systems share projection neurons but elicit distinct motor patterns. J Neurosci 24:11381-11390.

Borst A, Haag J (2001) Effects of mean firing on neural information rate. J Comput Neurosci 10:213-221.

Bryant HL, Segundo JP (1976) Spike initiation by transmembrane current: a white-noise analysis. J Physiol (Lond) 260:279-314.

Bush BM (1965) Proprioception by the coxo-basal chordotonal organ, CB, in legs of the crab, Carcinus maenas. J Exp Biol 42:285-297.

Cecchi GA, Sigman M, Alonso JM, Martinez L, Chialvo DR, Magnasco MO (2000) Noise in neurons is message dependent. Proc Natl Acad Sci USA 97:5557-5561.

Combes D, Simmers J, Moulins M (1997) Conditional dendritic oscillators in a lobster mechanoreceptor neurone. J Physiol (Lond) 499:161-177.

deCharms RC, Zador A (2000) Neural representation and the cortical code. Annu Rev Neurosci 23:613-647. de Ruyter van Steveninck RR, Lewen GD, Strong SP, Koberle R, Bialek W (1997) Reproducibility and variability in neural spike trains. Science 275:1805-1808.

Diba K, Lester HA, Koch C (2004) Intrinsic noise in cultured hippocampal neurons: experiment and modeling. J Neurosci 24:9723-9733.

DiCaprio RA (2003) Nonspiking and spiking proprioceptors in the crab: nonlinear analysis of nonspiking TCMRO afferents. J Neurophysiol 89:1826-1836.

Duve H, Johnsen AH, Maestro JL, Scott AG, Jaros PP, Thorpe A (1997) Isolation and identification of multiple neuropeptides of the allatostatin superfamily in the shore crab Carcinus maenas. Eur J Biochem 250:727-734.

Elhilali M, Fritz JB, Klein DJ, Simon JZ, Shamma SA (2004) Dynamics of precise spike timing in primary auditory cortex. J Neurosci 24:1159-1172.

el Manira A, Rossi-Durand C, Clarac F (1991) Serotonin and proctolin modulate the response of a stretch receptor in crayfish. Brain Res 541:157-162.

Fellous JM, Houweling AR, Modi RH, Rao RP, Tiesinga PH, Sejnowski TJ (2001) Frequency dependence of spike timing reliability in cortical pyramidal cells and interneurons. J Neurophysiol 85:1782-1787.

Fujisawa S, Yamada MK, Nishiyama N, Matsuki N, Ikegaya Y (2004) BDNF boosts spike fidelity in chaotic neural oscillations. Biophys J 86:1820-1828.

Gamble ER, DiCaprio RA (2003) Nonspiking and spiking proprioceptors in the crab: white noise analysis of spiking CB-chordotonal organ afferents. J Neurophysiol 89:1815-1825.

Grewe J, Kretzberg J, Warzecha AK, Egelhaaf M (2003) Impact of photon noise on the reliability of a motion-sensitive neuron in the fly's visual system. J Neurosci 23:10776-10783.

Heil P (1997) Auditory cortical onset responses revisited. I. First-spike timing. J Neurophysiol 77:2616-2641.

Hofmann T, Koch UT (1985) Acceleration receptors in the femoral chordotonal organ of the stick insect, Cuniculina impigra. J Exp Biol 114:225-237.

Hunter JD, Milton JG (2003) Amplitude and frequency dependence of spike timing: implications for dynamic regulation. J Neurophysiol 90:387-394.

Hunter JD, Milton JG, Thomas PJ, Cowan JD (1998) Resonance effect for neural spike time reliability. J Neurophysiol 80:1427-1438.

Hurley LM, Pollak GD (2005) Serotonin shifts first-spike latencies of inferior colliculus neurons. J Neurosci 25:7876-7886.

Jacobson GA, Diba K, Yaron-Jakoubovitch A, Oz Y, Koch C, Segev I, Yarom Y (2005) Subthreshold voltage noise of rat neocortical pyramidal neurones. J Physiol (Lond) 564:145-160.

Katz PS, Harris-Warrick RM (1989) Serotonergic/cholinergic muscle receptor cells in the crab stomatogastric nervous system. II. Rapid nicotinic and prolonged modulatory effects on neurons in the stomatogastric ganglion. J Neurophysiol 62:571-581.

Katz PS, Harris-Warrick RM (1990) Neuromodulation of the crab pyloric central pattern generator by serotonergic/cholinergic proprioceptive afferents. J Neurosci 10:1495-1512.

Katz PS, Harris-Warrick RM (1991) Recruitment of crab gastric mill neurons into the pyloric motor pattern by mechanosensory afferent stimulation. J Neurophysiol 65:1442-1451.

Katz PS, Eigg MH, Harris-Warrick RM (1989) Serotonergic/cholinergic muscle receptor cells in the crab stomatogastric nervous system. I. Identification and characterization of the gastropyloric receptor cells. J Neurophysiol 62:558-570.

Le Bon-Jego M, Cattaert D, Pearlstein E (2004) Serotonin enhances the resistance reflex of the locomotor network of the crayfish through multiple modulatory effects that act cooperatively. J Neurosci 24:398-411.

Lewen GD, Bialek W, de Ruyter van Steveninck RR (2001) Neural coding of naturalistic motion stimuli. Network 12:317-329.

Li L, Kelley WP, Billimoria CP, Christie AE, Pulver SR, Sweedler JV, Marder E (2003) Mass spectrometric investigation of the neuropeptide complement and release in the pericardial organs of the crab, Cancer borealis. J Neurochem 87:642-656.

Liu RC, Tzonev S, Rebrik S, Miller KD (2001) Variability and information in a neural code of the cat lateral geniculate nucleus. J Neurophysiol 86:2789-2806.

MacKay D, McCulloch WS (1952) The limiting information capacity of a neuronal link. Bull Math Biophys 14:127-135. 
Mainen ZF, Sejnowski TJ (1995) Reliability of spike timing in neocortical neurons. Science 268:1503-1506.

Maršálek P, Koch C, Maunsell J (1997) On the relationship between synaptic input and spike output jitter in individual neurons. Proc Natl Acad Sci USA 94:735-740.

Matheson T (1997) Octopamine modulates the responses and presynaptic inhibition of proprioceptive sensory neurones in the locust Schistocerca gregaria. J Exp Biol 200:1317-1325.

Maynard DM, Dando MR (1974) The structure of the stomatogastric neuromuscular system in Callinectes sapidus, Homarus americanus and Panulirus argus (Decapoda Crustacea). Philos Trans R Soc Lond B Biol Sci 268:161-220.

Mill PJ (1976) Chordotonal organs of crustacean appendages. In: Structure and function of proprioceptors in the invertebrates (Mill PJ, ed), pp 243297. London: Chapman and Hall.

Nowak LG, Sanchez-Vives MV, McCormick DA (1997) Influence of low and high frequency inputs on spike timing in visual cortical neurons. Cereb Cortex 7:487-501.

Pasztor VM, Bush BM (1987) Peripheral modulation of mechanosensitivity in primary afferent neurons. Nature 326:793-795.

Pasztor VM, Bush BM (1989) Primary afferent responses of a crustacean mechanoreceptor are modulated by proctolin, octopamine, and serotonin. J Neurobiol 20:234-254.

Phillips DP, Hall SE, Boehnke SE (2002) Central auditory onset responses, and temporal asymmetries in auditory perception. Hear Res 167:192-205.

Prinz AA, Abbott LF, Marder E (2004) The dynamic clamp comes of age. Trends Neurosci 27:218-224.

Ramirez J, Büschges A, Kittmann R (1993) Octopaminergic modulation of the femoral chordotonal organ in the stick insect. J Comp Physiol A Neuroethol Sens Neural Behav Physiol 173:209-219.

Redman SJ, Lampard DG, Annal P (1968) Monosynaptic stochastic stimulation of cat spinal motoneurons. II. Frequency transfer characteristics of tonically discharging motoneurons. J Neurophysiol 31:499-508.

Reinagel P, Reid RC (2000) Temporal coding of visual information in the thalamus. J Neurosci 20:5392-5400.

Reinagel P, Reid RC (2002) Precise firing events are conserved across neurons. J Neurosci 22:6837-6841.

Rieke F, Warland D, de Ruyter van Steveninck RR, Bialek W (1997) Spikes: exploring the neural code. Cambridge, MA: MIT.

Rokem A, Watzl S, Gollisch T, Stemmler M, Herz AV, Samengo I (2006) Spike-timing precision underlies the coding efficiency of auditory receptor neurons. J Neurophysiol 95:2541-2552.

Rossi-Durand C (1993) Peripheral proprioceptive modulation in crayfish walking leg by serotonin. Brain Res 632:1-15.

Sanderson AC, Kozak WM, Calvert TW (1973) Distribution coding in the visual pathway. Biophys J 13:218-244.
Schneidman E, Freedman B, Segev I (1998) Ion channel stochasticity may be critical in determining the reliability and precision of spike timing. Neural Comput 10:1679-1703.

Schreiber S, Fellous JM, Tiesinga P, Sejnowski TJ (2004) Influence of ionic conductances on spike timing reliability of cortical neurons for suprathreshold rhythmic inputs. J Neurophysiol 91:194-205.

Segundo JP, Perkel DH, Moore GP (1966) Spike probability in neurones: influence of temporal structure in the train of synaptic events. Kybernetik 3:67-82.

Sharp AA, O’Neil MB, Abbott LF, Marder E (1993) Dynamic clamp: computer-generated conductances in real neurons. J Neurophysiol 69:992-995.

Skiebe P, Schneider H (1994) Allatostatin peptides in the crab stomatogastric nervous system: inhibition of the pyloric motor pattern and distribution of allatostatin-like immunoreactivity. J Exp Biol 194:195-208.

Steinmetz PN, Manwani A, Koch C, London M, Segev I (2000) Subthreshold voltage noise due to channel fluctuations in active neuronal membranes. J Comput Neurosci 9:133-148.

Strawn JR, Neckameyer WS, Cooper RL (2000) The effects of 5-HT on sensory, central and motor neurons driving the abdominal superficial flexor muscles in the crayfish. Comp Biochem Physiol B 127:533-550.

Strong S, Koberle R, de Ruyter van Steveninck RR, Bialek W (1998) Entropy and information and in neural spike trains. Phys Rev Lett 80:197-200.

Szücs A, Vehovszky A, Molnar G, Pinto RD, Abarbanel HD (2004) Reliability and precision of neural spike timing: simulation of spectrally broadband synaptic inputs. Neuroscience 126:1063-1073.

Tang AC, Wolfe J, Bartels AM (1999) Cholinergic modulation of spike timing and spike rate. Neurocomputing 26-27:293-298.

Theunissen F, Miller JP (1995) Temporal encoding in nervous systems: a rigorous definition. J Comput Neurosci 2:149-162.

Uzzell VJ, Chichilnisky EJ (2004) Precision of spike trains in primate retinal ganglion cells. J Neurophysiol 92:780-789.

Werner G, Mountcastle VB (1965) Neural activity in mechanoreceptive cutaneous afferents: stimulus-response relations, Weber functions, and information transmission. J Neurophysiol 28:359-397.

White JA, Klink R, Alonso A, Kay AR (1998) Noise from voltage-gated ion channels may influence neuronal dynamics in the entorhinal cortex. J Neurophysiol 80:262-269.

White JA, Rubinstein JT, Kay AR (2000) Channel noise in neurons. Trends Neurosci 23:131-137.

Widmer A, Höger U, Meisner S, French AS, Torkkeli PH (2005) Spider peripheral mechanosensory neurons are directly innervated and modulated by octopaminergic efferents. J Neurosci 25:1588-1598.

Zhang BG, Torkkeli PH, French AS (1992) Octopamine selectively modifies the slow component of sensory adaptation in an insect mechanoreceptor. Brain Res 591:351-355. 